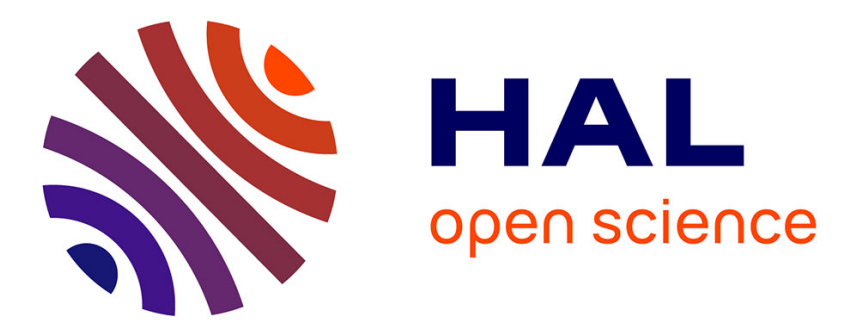

\title{
Elastic Stress Field beneath an arbitrary axisymmetric punch
}

Jacques Woirgard, Valerie Audurier, Christophe Tromas

\section{To cite this version:}

Jacques Woirgard, Valerie Audurier, Christophe Tromas. Elastic Stress Field beneath an arbitrary axisymmetric punch. Philosophical Magazine, 2008, 88 (10), pp.1511-1523. 10.1080/14786430802206474 . hal-00513906

\section{HAL Id: hal-00513906 https://hal.science/hal-00513906}

Submitted on 1 Sep 2010

HAL is a multi-disciplinary open access archive for the deposit and dissemination of scientific research documents, whether they are published or not. The documents may come from teaching and research institutions in France or abroad, or from public or private research centers.
L'archive ouverte pluridisciplinaire HAL, est destinée au dépôt et à la diffusion de documents scientifiques de niveau recherche, publiés ou non, émanant des établissements d'enseignement et de recherche français ou étrangers, des laboratoires publics ou privés. 


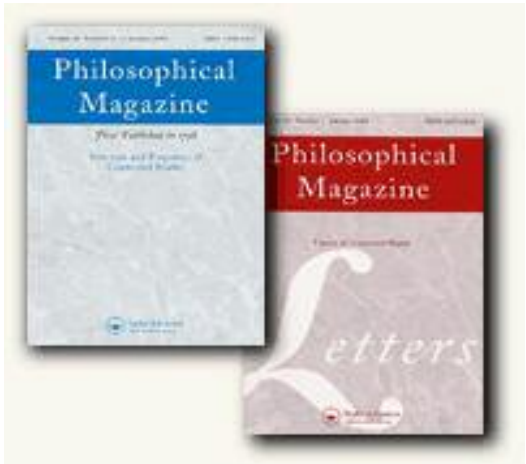

Elastic Stress Field beneath an arbitrary axisymmetric punch

\begin{tabular}{|c|c|}
\hline Journal: & Philosophical Magazine \& Philosophical Magazine Letters \\
\hline Manuscript ID: & TPHM-07-Apr-0102.R2 \\
\hline Journal Selection: & Philosophical Magazine \\
\hline $\begin{array}{r}\text { Date Submitted by the } \\
\text { Author: }\end{array}$ & 24-Apr-2008 \\
\hline Complete List of Authors: & $\begin{array}{l}\text { Woirgard, Jacques; Universite de Poitiers, Laboratoire de } \\
\text { Metallurgie Physique UMR } 6630 \text { CNRS } \\
\text { Audurier, Valerie; Universite de Poitiers, Laboratoire de Metallurgie } \\
\text { Physique UMR } 6630 \text { CNRS } \\
\text { Tromas, Christophe; Universite de Poitiers, Laboratoire de } \\
\text { Metallurgie Physique UMR } 6630 \text { CNRS }\end{array}$ \\
\hline Keywords: & hardness, mechanical testing, nanoindentation \\
\hline Keywords (user supplied): & hardness, mechanical testing, nanoindentation \\
\hline
\end{tabular}

\section{\$) ScholarONE \\ Manuscript Central}




\title{
Elastic stress field beneath an arbitrary axisymmetric punch
}

\author{
J. Woirgard, V. Audurier, C. Tromas
}

Laboratoire de Métallurgie Physique, Université de Poitiers SP2MI, UMR CNRS 6630, 86962 Futuroscope-Chasseneuil, France

\begin{abstract}
.
The nanoindentation test is commonly used for the local determination of mechanical properties (hardness, Elastic modulus, ...) and also to study the initial stages of plasticity (dislocation nucleation, dislocation interaction mechanisms) at nanometer scale. In that case, the determination of the elastic stress field beneath the indenter is of primary interest. The purpose of this paper is to give an analytical expression for the elastic stress and strain fields beneath an axisymetric punch. Most solutions, in the literature, are given for simple indenter shapes, such as flat, conical or spherical indenters. Complete
\end{abstract}


solution for arbitrary indenter profile described by a power law, with exponent integer or not, is proposed here. The stress is given as the real part of complex analytical expressions.

\section{Introduction}

Over the last two decades, the nanoindentation test has become a common technique for the determination of local mechanical properties such as hardness and elastic modulus [1-4]. The principle consists in applying a low load with an indenter on the surface while the progressive penetration depth is monitored. The main experimental parameter for hardness and elastic modulus determination is the contact area between the indenter and the surface under load. Several models have been proposed to determine this crucial parameter through the analysis of the unloading curve shape. One of the first attempts has been given by Doerner and Nix [6] who considered that the contact area was not modified during an elastic unloading, as for a flat punch. In a more realistic approach, , Oliver and Pharr [2] proposed to determine the initial value of the contact area by taking into account its variation during elastic unloading. For this purpose, the principle of the equivalent indenter, assumed to be parabolic was used. This principle, initially introduced by Solomon [7], suggests that the elastic unloading of an indenter on a plastically deformed surface is equivalent to that of a "modified" indenter giving the same displacement when pressed against a plane. However, the shape of the equivalent indenter which depends on the plastic behaviour of the material, is more complex than a paraboloid and 
should be determined for each unloading. One method consists in describing the equivalent indenter shape by a polynomial [4,8-9] in cylindrical coordinates $(\rho, z)$ :

$$
z(\rho)=\sum_{n} C_{n} \rho^{n}
$$

In this case, for a rigid indenter the load $\mathrm{P}$ and the displacement $\mathrm{h}$ are functions of the contact radius a $[10-11]$ :

$$
\begin{aligned}
& \mathrm{h}(\mathrm{a})=\sqrt{\pi} \sum_{\mathrm{n}} \frac{\Gamma\left(\frac{\mathrm{n}}{2}+1\right)}{\Gamma\left(\frac{\mathrm{n}}{2}+\frac{1}{2}\right)} \mathrm{C}_{\mathrm{n}} \mathrm{a}^{\mathrm{n}} \\
& \mathrm{P}(\mathrm{a})=2 \mathrm{E}_{\mathrm{r}} \sqrt{\pi} \sum_{\mathrm{n}} \frac{\mathrm{n}}{\mathrm{n}+1} \frac{\Gamma\left(\frac{\mathrm{n}}{2}+1\right)}{\Gamma\left(\frac{\mathrm{n}}{2}+\frac{1}{2}\right)} \mathrm{C}_{\mathrm{n}} \mathrm{a}^{\mathrm{n}}
\end{aligned}
$$

where $\Gamma$ is the gamma function and $E_{r}$ is the reduced modulus defined by

$$
\mathrm{E}_{\mathrm{r}}=\frac{\mathrm{E}}{1-v^{2}}
$$

with $E$ and $v$ the Young's modulus and the Poisson's ratio of the sample respectively. It has been shown elsewhere [4], that with the stiffness:

$$
\mathrm{S}=\frac{\mathrm{dP}}{\mathrm{dh}}
$$

the penetration-stiffness relation can be fitted by a polynomial:

$$
\mathrm{h}(\mathrm{S})=\frac{\sqrt{\pi}}{\left(2 \mathrm{E}_{\mathrm{r}}\right)^{\mathrm{n}}} \sum_{\mathrm{n}} \frac{\Gamma\left(\frac{\mathrm{n}}{2}+1\right)}{\Gamma\left(\frac{\mathrm{n}}{2}+\frac{1}{2}\right)} \mathrm{C}_{\mathrm{n}} \mathrm{S}^{\mathrm{n}}
$$

allowing the determination of the $\mathrm{C}_{\mathrm{n}}$ coefficients and the $\mathrm{n}$ exponents.

Unloading curves can often be fitted by simple power law

$$
\mathrm{P}(\mathrm{h})=\alpha\left(\mathrm{h}-\mathrm{h}_{0}\right)^{\mathrm{m}}
$$


where $h_{0}$ is the residual penetration depth. In this case, the shape function of the equivalent indenter reduces to a single term with a non integer exponent $n$ $\mathrm{z}(\mathrm{r})=\mathrm{Cr} \mathrm{r}^{\mathrm{n}}$

The corresponding load-displacement relationship being:

$\mathrm{P}(\mathrm{h})=\frac{2 \mathrm{E}_{\mathrm{r}}}{(\sqrt{\pi} \mathrm{C})^{\frac{1}{\mathrm{n}}}} \frac{\mathrm{n}}{\mathrm{n}+1} \frac{\Gamma\left(\frac{\mathrm{n}}{2}+\frac{1}{2}\right)}{\Gamma\left(\frac{\mathrm{n}}{2}+1\right)} \mathrm{h}^{1+\frac{1}{\mathrm{n}}}$

The relation between the unloading curve exponent $\mathrm{m}$ and the indenter shape exponent $\mathrm{n}$ is thus given by:

$\mathrm{n}=\frac{1}{\mathrm{~m}-1}$

This method is commonly used to estimate the true penetration depth and thus the contact area under load $A_{c}$. The hardness $H$ and the reduced elastic modulus $E_{r}$ are then easily determined through the equations

$$
\begin{aligned}
& H=\frac{P}{A_{c}} \\
& S=2 E_{r} \frac{\sqrt{A_{c}}}{\pi}
\end{aligned}
$$

Beside the determination of elasto-plastic characteristics of materials, nanoindentation is also of fundamental interest for studying elementary deformation mechanisms and incipient plasticity, involving small material volumes and few dislocations[12-21]. The precise knowledge of the stress field generated in the material is required to understand the individual behaviour of these defects [20]. The surface stress has been previously calculated in the 
case of an elastic contact between a flat surface and an axisymetric indenter [22-23], or a more complex indenter described by a power function with a non integer exponent $n[4,5,24]$. This latter case is of great interest since it can be applied to any unloading curve, even for plastically deformed material, through the concept of the equivalent indenter [7].

In the following, analytical solutions will be proposed for the calculation of the complete stress field in the case of arbitrary shaped axysimetric indenters.

\section{Theoretical results}

Close form expressions of the stress field, either on the surface or in the volume, beneath simple indenters, including flat punches, cones or spheres have been previously published [25-30], but very few results are available for more complex profiles, except a recent work of Schwarzer [31-32] proposing a partial solution in the case of axisymetric punches described by polynomials. However this theory, named the "extended Hertzian theory", is limited to even power of $r$ which cannot be applied to real equivalent indenters with non integer exponent. For more complex shapes, the only results, to our best knowledge, have been obtained by finite element methods (FEM) [33-34].

In this work, Sneddon's [22,35] results, will be used to determine the complete stress fields in the quite general case of power laws with exponents integer or not. 
Sneddon [36] showed that the normal stress and displacements can be derived from the $f(t)$ function, solution of the dual integral equation:

$u_{z}(r)=-\frac{(\lambda+2 \mu) a}{\mu} \int_{0}^{\infty} f(t) J_{0}(r t) d t=f(r)=h-c a^{n} r^{n} \quad$ for $r \leq 1$

$\sigma_{z}(r)=2(\lambda+\mu) \int_{0}^{\infty} t f(t) J_{0}(r t) d t=0 \quad$ for $r \geq 1$

With

$r=\frac{\rho}{a}$

And $\lambda$ and $\mu$ the Lame's coefficient. To find a $f(t)$ function satisfying the preceding equations, Sneddon proposed to introduce the function $g(u)$ obeying:

$f(t)=\int_{0}^{1} g(u) \cos (u t) d u$

With this form of function $g(u)$ we find that:

$\int_{0}^{\infty} t f(t) J_{0}(r t) d t=\int_{0}^{\infty} J_{0}(r t) d t \int_{0}^{1} t g(u) \cos (u t) d u$

and integrating by parts:

$\int_{0}^{\infty} \mathrm{tf}(\mathrm{t}) \mathrm{J}_{0}(\mathrm{rt}) \mathrm{dt}=\mathrm{g}(1) \int_{0}^{\infty} \mathrm{J}_{0}(\mathrm{rt}) \sin (\mathrm{t}) \mathrm{dt}-\int_{0}^{\infty} \mathrm{J}_{0}(\mathrm{rt}) \mathrm{dt} \int_{0}^{1} \frac{\partial \mathrm{g}(\mathrm{u})}{\partial \mathrm{u}} \sin (\mathrm{ut}) \mathrm{du} \quad(\mathrm{r}>1)$

Interchanging the order of integration in the double integral and knowing that:

$\int_{0}^{\infty} J_{0}(r t) \sin (u t) d t=0$

we see that equation (14) is satisfied and we must have $g(1)=0$ since:

$\sigma_{z}=0$ for $r=1$

Equation (13) can be written:

$-\frac{(\lambda+2 \mu) a}{\mu} \int_{0}^{\infty} J_{0}(r t) d t \int_{0}^{1} g(u) \cos (u t) d u=h-c a^{n} r^{n}$ 
If we interchange the order of integration and make use of:

$$
\begin{array}{ll}
\int_{0}^{\infty} J_{0}(r t) \cos (u t) d t=\frac{1}{\sqrt{r^{2}-u^{2}}} & (r>u) \\
\int_{0}^{\infty} J_{0}(r t) \cos (u t) d t=0 & (0<r<u)
\end{array}
$$

we see that $g(u)$ is a solution of the integral equation:

$$
-\frac{(\lambda+2 \mu) \mathrm{a}}{\mu} \int_{0}^{\mathrm{r}} \frac{\mathrm{g}(\mathrm{u}) \mathrm{du}}{\sqrt{\mathrm{r}^{2}-\mathrm{u}^{2}}}=\mathrm{h}-\mathrm{Ca}^{\mathrm{n}} \mathrm{r}^{\mathrm{n}}
$$

We can try for $g(u)$ :

$$
\mathrm{g}(\mathrm{u})=\mathrm{A}+\mathrm{Bu} \mathrm{u}^{\mathrm{n}}
$$

and equation (20) may be written :

$$
\int_{0}^{\mathrm{r}} \frac{\mathrm{g}(\mathrm{u}) \mathrm{du}}{\sqrt{\mathrm{r}^{2}-\mathrm{u}^{2}}}=\mathrm{A} \frac{\pi}{2}+\mathrm{B} \frac{\sqrt{\pi} \Gamma\left(\frac{\mathrm{n}+1}{2}\right)}{2 \Gamma\left(\frac{\mathrm{n}}{2}+1\right)} \mathrm{r}^{\mathrm{n}}
$$

We finally get:

$$
\begin{aligned}
& \mathrm{A}=-\frac{2}{\pi} \frac{\mu}{(\lambda+2 \mu) \mathrm{a}} \mathrm{h} \\
& \mathrm{B}=\frac{\mu}{(\lambda+2 \mu) \mathrm{a}} \frac{2 \Gamma\left(\frac{\mathrm{n}}{2}+1\right)}{\sqrt{\pi} \Gamma\left(\frac{\mathrm{n}+1}{2}\right)} \mathrm{Ca}^{\mathrm{n}}
\end{aligned}
$$

Since $g(1)=0$ we have:

$$
\mathrm{h}=\sqrt{\pi} \frac{\Gamma\left(\frac{\mathrm{n}}{2}+1\right)}{\Gamma\left(\frac{\mathrm{n}+1}{2}\right)} \mathrm{Ca}^{\mathrm{n}}
$$

and:

$$
\mathrm{g}(\mathrm{u})=-\frac{2 \mu}{(\lambda+2 \mu) \mathrm{a}} \frac{\Gamma\left(\frac{\mathrm{n}}{2}+1\right)}{\sqrt{\pi} \Gamma\left(\frac{\mathrm{n}+1}{2}\right)} \mathrm{Ca}^{\mathrm{n}}\left(1-\mathrm{u}^{\mathrm{n}}\right)
$$


$f(t)=-\frac{2 \mu}{(\lambda+2 \mu) a} \frac{\Gamma\left(\frac{n}{2}+1\right)}{\sqrt{\pi} \Gamma\left(\frac{n+1}{2}\right)} C a^{n} \int_{0}^{1}\left(1-u^{n}\right) \cos (t u) d u$

Let $\mathrm{k}$ be :

$\mathrm{k}=-\frac{2 \mu}{(\lambda+2 \mu) \mathrm{a}} \frac{\Gamma\left(\frac{\mathrm{n}}{2}+1\right)}{\sqrt{\pi} \Gamma\left(\frac{\mathrm{n}+1}{2}\right)} \mathrm{Ca}^{\mathrm{n}}$

We see that $f(t)$ is the real part of the complex quantity:

$f^{*}(t)=k \int_{0}^{1}\left(1-u^{n}\right) e^{-i u t} d u$

To compute the stress field we have to evaluate the following complex integrals:

$$
\begin{aligned}
& I^{*}=\int_{0}^{\infty} e^{-z t} t^{*}(t) J_{0}(r t) d t \\
& K^{*}=\int_{0}^{\infty} e^{-z t} t f^{*}(t) J_{1}(r t) d t
\end{aligned}
$$

and the components of the stresses are the real parts of the complex stresses:

$$
\begin{aligned}
& \sigma_{z}^{*}=2 k(\lambda+\mu)\left(-\frac{\partial I^{*}}{\partial z}+z \frac{\partial^{2} I^{*}}{\partial z^{2}}\right) \\
& \tau_{r}^{*}=2 k(\lambda+\mu) z \frac{\partial^{2} K^{*}}{\partial z^{2}} \\
& \sigma_{\theta}^{*}=-2 k \lambda \frac{\partial I^{*}}{\partial z}+\frac{2 \mu}{r} k\left(K^{*}+\frac{\mu+\lambda}{\mu} z \frac{\partial K^{*}}{\partial z}\right) \\
& \sigma_{r}^{*}+\sigma_{\theta}^{*}=-2 k(\lambda+\mu)\left(\frac{2 \lambda+\mu}{\lambda+\mu} \frac{\partial I^{*}}{\partial z}+z \frac{\partial^{2} I^{*}}{\partial z^{2}}\right)
\end{aligned}
$$

These components of the stress are easily derived from the $\mathrm{I}^{*}$ and $\mathrm{K}^{*}$ integrals and their derivatives relative to $\mathrm{z}$ :

$$
\begin{aligned}
& I^{*}=\int_{0}^{1}\left(1-u^{n}\right) d u \int_{0}^{\infty} e^{-(z+i u) t} J_{0}(r t) d t \\
& K^{*}=\int_{0}^{1}\left(1-u^{n}\right) d u \int_{0}^{\infty} e^{-(z+i u) t} J_{1}(r t) d t
\end{aligned}
$$


If we note:

$$
\begin{aligned}
& \mathrm{p}_{0}^{*}=\int_{0}^{\infty} \mathrm{e}^{-(\mathrm{z}+\mathrm{iu}) \mathrm{t}} \mathrm{J}_{0}(\mathrm{rt}) \mathrm{dt}=\frac{1}{\sqrt{\mathrm{r}^{2}+(\mathrm{iu}+\mathrm{z})^{2}}} \\
& \mathrm{p}_{1}^{*}=\int_{0}^{\infty} \mathrm{e}^{-(\mathrm{z}+\mathrm{iu}) \mathrm{t}} \mathrm{J}_{1}(\mathrm{rt}) \mathrm{dt}=\frac{1}{\mathrm{r}}-\frac{\mathrm{iu}+\mathrm{z}}{\mathrm{r} \sqrt{\mathrm{r}^{2}+(\mathrm{iu}+\mathrm{z})^{2}}}
\end{aligned}
$$

we can write:

$$
\begin{aligned}
& \mathrm{I}^{*}=\mathrm{I}_{0}^{*}-\mathrm{I}_{\mathrm{n}}^{*} \\
& \mathrm{~K}^{*}=\mathrm{K}_{0}^{*}-\mathrm{K}_{\mathrm{n}}^{*}
\end{aligned}
$$

with:

$$
\begin{aligned}
& \mathrm{I}_{0}^{*}=\int_{0}^{1} \mathrm{p}_{0}^{*} \mathrm{du} \\
& \mathrm{K}_{0}^{*}=\int_{0}^{1} \mathrm{p}_{1}^{*} \mathrm{du} \\
& \mathrm{I}_{\mathrm{n}}^{*}=\int_{0}^{1} \mathrm{p}_{0}^{*} \mathrm{u}^{\mathrm{n}} \mathrm{du} \\
& \mathrm{K}_{\mathrm{n}}^{*}=\int_{0}^{1} \mathrm{p}_{1}^{*} \mathrm{u}^{\mathrm{n}} \mathrm{du}
\end{aligned}
$$

Finally the integrals and their derivatives take the form:

$$
\begin{aligned}
& I_{0}^{*}=i \ln \frac{z+\sqrt{r^{2}+z^{2}}}{i+z+\sqrt{r^{2}+(i+z)^{2}}} \\
& \frac{\partial I_{0}^{*}}{\partial z}=\frac{i}{\sqrt{r^{2}+z^{2}}}-\frac{i}{\sqrt{r^{2}+(i+z)^{2}}} \\
& \frac{\partial^{2} I_{0}^{*}}{\partial z^{2}}=\frac{i z-1}{\left[r^{2}+(i+z)^{2}\right]^{\frac{3}{2}}}-\frac{i z}{\left(r^{2}+z^{2}\right)^{\frac{3}{2}}} \\
& K_{0}^{*}=\frac{1-i \sqrt{r^{2}+z^{2}}+i \sqrt{r^{2}+(i+z)^{2}}}{r}
\end{aligned}
$$




$$
\begin{aligned}
& \frac{\partial K_{0}^{*}}{\partial z}=\frac{i z-1}{r\left[r^{2}+(i+z)^{2}\right]^{\frac{3}{2}}}-\frac{i z}{r\left(r^{2}+z^{2}\right)^{\frac{3}{2}}} \\
& \frac{\partial^{2} K_{0}^{*}}{\partial z^{2}}=\frac{i r(i+z)}{\left[r^{2}+(i+z)^{2}\right]^{\frac{3}{2}}}-\frac{i r z}{\left(r^{2}+z^{2}\right)^{\frac{3}{2}}}
\end{aligned}
$$

Let us note, with $F_{1}\left(a, b, c, d, z_{1}, z_{2}\right)$ the Appell hypergeometric function:

$$
\begin{aligned}
& F_{n+1, \frac{1}{2}}=F_{1}\left(1+n, \frac{1}{2}, \frac{1}{2}, 2+n, \frac{1}{r+i z}, \frac{1}{-r+i z}\right) \\
& F_{n+2, \frac{1}{2}}=F_{1}\left(2+n, \frac{1}{2}, \frac{1}{2}, 3+n, \frac{1}{r+i z}, \frac{1}{-r+i z}\right) \\
& F_{n+1, \frac{3}{2}}=F_{1}\left(1+n, \frac{3}{2}, \frac{3}{2}, 2+n, \frac{1}{r+i z}, \frac{1}{-r+i z}\right) \\
& F_{n+2, \frac{3}{2}}=F_{1}\left(2+n, \frac{3}{2}, \frac{3}{2}, 3+n, \frac{1}{r+i z}, \frac{1}{-r+i z}\right) \\
& F_{n+1, \frac{5}{2}}=F_{1}\left(1+n, \frac{5}{2}, \frac{5}{2}, 2+n, \frac{1}{r+i z}, \frac{1}{-r+i z}\right) \\
& F_{n+2, \frac{5}{2}}=F_{1}\left(2+n, \frac{5}{2}, \frac{5}{2}, 3+n, \frac{1}{r+i z}, \frac{1}{-r+i z}\right) \\
& F_{n+3, \frac{5}{2}}=F_{1}\left(3+n, \frac{5}{2}, \frac{5}{2}, 4+n, \frac{1}{r+i z}, \frac{1}{-r+i z}\right)
\end{aligned}
$$

The real part of the $F_{1}$ function can be easily calculated with mathematical packages. Then, we can write:

$$
\begin{aligned}
& I_{n}^{*}=\frac{F_{n+1, \frac{1}{2}}}{(1+n) \sqrt{r^{2}+z^{2}}} \\
& \frac{\partial I_{n}^{*}}{\partial z}=\frac{1}{\left(r^{2}+z^{2}\right)^{\frac{3}{2}}}\left(\frac{F_{n+1, \frac{3}{2}}}{n+1}+\frac{F_{n+2, \frac{3}{2}}}{n+2}\right) \\
& \frac{\partial^{2} I_{n}^{*}}{\partial z^{2}}=\frac{1}{(n+1)\left(r^{2}+z^{2}\right)^{\frac{5}{2}}}\left[2\left(r^{2}+z^{2}\right) F_{n+1, \frac{3}{2}}-3 r^{2} F_{n+1, \frac{5}{2}}\right]
\end{aligned}
$$




$$
\begin{aligned}
& \mathrm{K}_{\mathrm{n}}^{*}=\frac{1}{(\mathrm{n}+1) \mathrm{r}}-\frac{1}{\mathrm{r} \sqrt{\mathrm{r}^{2}+\mathrm{z}^{2}}}\left(\frac{\mathrm{z}}{\mathrm{n}+1} \mathrm{~F}_{\mathrm{n}+1, \frac{1}{2}}+\frac{\mathrm{i}}{\mathrm{n}+2} \mathrm{~F}_{\mathrm{n}+2, \frac{1}{2}}\right) \\
& \frac{\partial \mathrm{K}_{\mathrm{n}}^{*}}{\partial \mathrm{z}}=-\frac{\mathrm{r}}{(\mathrm{n}+1)\left(\mathrm{r}^{2}+\mathrm{z}^{2}\right)^{\frac{3}{2}}} \mathrm{~F}_{\mathrm{n}+1, \frac{3}{2}} \\
& \frac{\partial^{2} \mathrm{~K}_{\mathrm{n}}^{*}}{\partial \mathrm{z}^{2}}=\frac{3 \mathrm{r}}{\left(\mathrm{r}^{2}+\mathrm{z}^{2}\right)^{\frac{5}{2}}}\left(\frac{\mathrm{z}}{\mathrm{n}+1} \mathrm{~F}_{\mathrm{n}+1, \frac{5}{2}}+\frac{\mathrm{i}}{\mathrm{n}+2} \mathrm{~F}_{\mathrm{n}+2, \frac{5}{2}}\right)
\end{aligned}
$$

The formulae are undetermined when $\mathrm{n}$ is an integer, but in that case we can use a recurrence relationship:

$$
\begin{aligned}
& I_{n}^{*}=-\frac{\sqrt{r^{2}+(i+z)^{2}}}{n}+\frac{n-1}{n}\left(r^{2}+z^{2}\right) I_{n-2}^{*}+\frac{2 n-1}{n} i z I_{n-1}^{*} \\
& K_{n}^{*}=\frac{1}{(n+1) r}\left[1+i \sqrt{r^{2}+(i+z)^{2}}-n i\left(r^{2}+z^{2}\right) I_{n-1}^{*}+n z I_{n}^{*}\right]
\end{aligned}
$$

with:

$$
\begin{aligned}
& I_{0}^{*}=i \ln \frac{z+\sqrt{r^{2}+z^{2}}}{i+z+\sqrt{r^{2}+(i+z)^{2}}} \\
& I_{1}^{*}=\sqrt{r^{2}+z^{2}}-\sqrt{r^{2}+(i+z)^{2}}-z \ln \frac{z+\sqrt{r^{2}+z^{2}}}{i+z+\sqrt{r^{2}+(i+z)^{2}}} \\
& K_{0}^{*}=\frac{1-i \sqrt{r^{2}+z^{2}}+i \sqrt{r^{2}+(i+z)^{2}}}{r}
\end{aligned}
$$

Again, following equations (35-38), the stress components can be derived from the real parts and their first and second derivatives relative to $z$ of the expressions (43) and (44).

When the exponent $\mathrm{n}$ is an integer, the I and $\mathrm{K}$ integrals, real parts of the $\mathrm{I}^{*}$ and $\mathrm{K}^{*}$ complex ones, can be calculated knowing that:

$$
\sqrt{r^{2}+(i+z)^{2}}=a+i b
$$


$\log \left[i+z+\sqrt{r^{2}+(i+z)^{2}}\right]=\ln \sqrt{(z+a)^{2}+(1+b)^{2}}+i \operatorname{ArcCos}\left(\frac{z+a}{\sqrt{(z+a)^{2}+(1+b)^{2}}}\right)$

with:

$\mathrm{a}=\frac{\sqrt{\sqrt{\left.\mathrm{r}^{2}+\mathrm{z}^{2}-1\right)^{2}+4 \mathrm{z}^{2}}+\left(\mathrm{r}^{2}+\mathrm{z}^{2}-1\right)}}{\sqrt{2}}$
$\mathrm{~b}=\frac{\sqrt{\sqrt{\left.\mathrm{r}^{2}+\mathrm{z}^{2}-1\right)^{2}+4 \mathrm{z}^{2}}-\left(\mathrm{r}^{2}+\mathrm{z}^{2}-1\right)}}{\sqrt{2}}$

For $n=0$ (flat punch) equations (68) and (69) fail but we have [22]:

$f(t)=\frac{\sin t}{t}$

and the $\mathrm{I}$ and $\mathrm{K}$ integrals are the imaginary parts of:

$$
\begin{aligned}
& I^{*}=\int_{0}^{\infty} e^{(-z+i) t} J_{0}(r t) d t=\frac{1}{\sqrt{r^{2}+(i+z)^{2}}} \\
& K^{*}=\int_{0}^{\infty} e^{(-z+i) t} J_{1}(r t) d t=\frac{\sqrt{r^{2}+(i+z)^{2}}-(i+z)}{r}
\end{aligned}
$$

For example, the normal stress is the imaginary part of:

$$
\sigma_{z}^{*}=2 k(\lambda+\mu)\left(\frac{1}{\sqrt{r^{2}+(i+z)^{2}}}+\frac{z(i+z)}{\left[r^{2}+(i+z)^{2}\right]^{\frac{3}{2}}}\right)
$$

When $\mathrm{n}$ is different from zero we can use the (68) to (69) equations.

For example, for $n=1$ (cone):

$$
\sigma_{z}^{*}=-k(\lambda+\mu)\left[\frac{z}{\sqrt{r^{2}+z^{2}}}-\frac{z}{\sqrt{r^{2}+(i+z)^{2}}}+\ln \frac{i+z+\sqrt{r^{2}+(i+z)^{2}}}{z+\sqrt{r^{2}+z^{2}}}\right]
$$

For $n=2$ (paraboloid) :

$$
\sigma_{z}^{*}=-k(\lambda+\mu)\left[2 i \sqrt{r^{2}+(i+z)^{2}}-\frac{2 z}{\sqrt{r^{2}+(i+z)^{2}}}\right]
$$

For $n=3$ : 
$\sigma_{z}^{*}=k(\lambda+\mu)\left[\frac{3 z}{2} \sqrt{r^{2}+z^{2}}-\frac{3(i+z)}{2} \sqrt{r^{2}+(i+z)^{2}}-\frac{3 z}{\sqrt{r^{2}+(i+z)^{2}}}+\frac{3\left(r^{2}+2 z^{2}\right)}{2} \ln \frac{i+z+\sqrt{r^{2}+(i+z)^{2}}}{z+\sqrt{r^{2}+z}}\right]$ Values of the $\mathrm{I}$ and $\mathrm{K}$ integrals, for $\mathrm{n}=1$ to 5 , and listed in appendix.

Using equations (61) to (64), the normal stresses on the surface $(z=0)$ and below the surface $(z=a / 2)$, are plotted in Figures 1 and 2 for non integer values of $n: 1.5,2.5$ and 3.5 .

\section{Conclusion}

In this paper, analytical expressions have been proposed for the determination of the complete stress field generated by an arbitrary axisymetric indenter described by an exponent $n$, integer or not. This calculus is not restricted to elastic indentation, but can also be applied through the concept of the equivalent indenter to elasto-plastic contact. The elastic stress field can thus be readily obtained once the exponent $\mathrm{m}$ of the elastic unloading curve has been determined. One of the main interests of this study is to give the ability to determine the forces acting on individual dislocations involved in the imprint formation. As an example, this result can be applied in discrete dislocation dynamic (DDD) study of the indentation test. This result, combined with recent insights in the description of the complete microstructure generated during a nanoindentation test, represent a significant step towards the comprehension of the early plastic deformation mechanisms in materials. 


\section{Reference}

[1] A.C. Fischer-Cripps, Nanoindentation, 2nd edR, Springer-Verlag, New-York, 2004.

[2] W.C. Oliver and G.M. Pharr, J. Mater. Res. 7(1992), p. 1564.

[3]. W.C. Oliver and G.M. Pharr, J. Mater. Res. 19 (2004), p. 3.

[4] J. Woirgard and J.C. Dargenton, J. Mater. Res. 12 (1997), p. 2455.

[5] G.M. Pharr and A. Bolshakov, J. Mater. Res. 17 (2002), p. 2660.

[6] M.F. Doerner and W.D. Nix, J. Mater. Res. 4 (1986), p. 601.

[7] L. Solomon, Elasticité Linéaire, Masson, Paris, 1968, p. 60.

[8] N. Schwarzer, J. Phys. D : Appl. Phys 37 (2004), p. 2761.

[9] N. Schwarzer, F. Richter, and G. Hecht, Surf. Coat. Techn. 14 (1999), p. 292.

[10] I.A. Sneddon, Int. J. Engng. Sci. 3 (1965), p. 47.

[11] C.M. Segedin, Mathematika 4 (1957), p.156.

[12] W.W. Gerberich, J.C. Nelson, E.T. Lilleodden, P. Anderson, and J.T. Wyrobek, Acta Mater. 44(9) (1996), p. 3585.

[13] A.B. Mann and J.B. Pethica, Appl. Phys. Lett. 69 (1996), p. 907.

[14] D.F. Bahr, D.E . Wilson, and D.A. Crowson, J. Mater. Res. 14 (6) (1999), p. 2269.

[15] N.I. Tymiak, D.E. Kramer, D.F. Bahr, T.J. Wyrobek, and W.W. Gerberich, Acta Mater. 49 (6) (2001), p.1021. 
[16] J. Li, K.J. Van Vliet, T. Zhu, S. Yip, and S. Suresh, Nature 418 (2002), p. 307.

[17] Y. Gaillard, C. Tromas, and J. Woirgard, Phil. Mag. Let. 83 (2003), p. 553.

[18] Y. Gaillard, C. Tromas, and J. Woirgard, Acta Mater.51 (2003), p. 1059.

[19] C. Tromas, Y. Gaillard, and J. Woirgard, Phil. Mag. 86 (2006), p. 5595.

[20] Y. Gaillard, C. Tromas, and J. Woirgard, Acta Mater. 54 (2006), p. 1409.

[21] A.M. Minor, J.W Morris Jr., and E.A. Stach, Appl. Phys. Lett. 79 (2001), p. 1625.

[22] I.A Sneddon, Fourier Transforms, McGraw-Hill, New-York,1951.

[23] K.L. Johnson, Contact Mechanics, Cambridge University Press, Cambridge, 1985.

[24] V.I. Fabrikant, J. of Appl Mech. 55(1988), p. 604.

[25] G.M. Hamilton, Proc. Instn. Mech. Engrs 197C (1983), p. 53.

[26] A. Sackfield and D.A. Hills., J. of Strain Analysis (18) (1983), p. 101.

[27] A. Sackfield and D.A. Hills, J. of Strain Analysis (18) (1983), p. 195.

[28] M.T. Hanson, T. Johnson, J. of Tribology 115 (1993), p. 327.

[29] G.M. Hamilton and L.E. Goodman, J. of Applied Mechanics 6 (1966), p. 371.

[30] .M. Gladwell and I.A. Sneddon, Int. J. Engng. Sci. 7 (1969), p. 295.

[31] N. Schwarzer, Phil. Mag. 86 (2006), p. 5179.

[32] N. Schwarzer, Thin Solid Films 494 (2006), p. 168.

[33] P.L. Larsson, A.E. Giannakopoulos, E.B. Söderlund, D.J. Rowcliffe, and R. Vestergaard, Int. J. Solids Structures 33 (1996), p. 221

[34] J.C. Hay, A. Bolshakov and G.M. Pharr, J. Mater. Res. 14 (1999), p. 2296. 
[35] I.A. Sneddon, Int. J. Engng. Sci. 3 (1965), p. 47.

[36] I.A Sneddon, Proc. Glasgow Math. Assoc. 4 (1951), p. 108. 


\section{Appendix}

$n=0$ :

$I_{0}^{*}=-i \ln \frac{i+z+\sqrt{r^{2}+(i+z)^{2}}}{z+\sqrt{r^{2}+z^{2}}}$

$\mathrm{K}_{0}^{*}=\frac{1}{\mathrm{r}}-\frac{\mathrm{i} \sqrt{\mathrm{r}^{2}+\mathrm{z}^{2}}}{\mathrm{r}}+\frac{\mathrm{i} \sqrt{\mathrm{r}^{2}+(\mathrm{i}+\mathrm{z})^{2}}}{\mathrm{r}}$

$n=1:$

$I_{1}^{*}=\sqrt{r^{2}+z^{2}}-\sqrt{r^{2}+(i+z)^{2}}+z \ln \frac{i+z+\sqrt{r^{2}+(i+z)^{2}}}{z+\sqrt{r^{2}+z^{2}}}$

$\mathrm{K}_{1}^{*}=\frac{1}{2 \mathrm{r}}+\frac{\mathrm{z}}{2 \mathrm{r}} \sqrt{\mathrm{r}^{2}+\mathrm{z}^{2}}+\frac{\mathrm{i}+\mathrm{z}}{2 \mathrm{r}} \sqrt{\mathrm{r}^{2}+(\mathrm{i}+\mathrm{z})^{2}}-\frac{1}{2 \mathrm{r}} \ln \frac{\mathrm{i}+\mathrm{z}+\sqrt{\mathrm{r}^{2}+(\mathrm{i}+\mathrm{z})^{2}}}{\mathrm{z}+\sqrt{\mathrm{r}^{2}+\mathrm{z}^{2}}}$

$n=2$ :

$I_{2}^{*}=\frac{3}{2} i z \sqrt{r^{2}+z^{2}}-\left(\frac{1}{2}+\frac{3 i z}{2}\right) \sqrt{r^{2}+(i+z)^{2}}-\left(\frac{i r^{2}}{2}-i z^{2}\right) \ln \frac{i+z+\sqrt{r^{2}+(i+z)^{2}}}{z+\sqrt{r^{2}+z^{2}}}$

$K_{2}^{*}=\left(-\frac{2 i r}{3 r}+\frac{i z^{2}}{3 r}\right) \sqrt{r^{2}+z^{2}}+\left(\frac{i}{3 r}+\frac{2 i r}{3}-\frac{z}{3 r}+\frac{i z^{2}}{3 r}\right) \sqrt{r^{2}+(i+z)^{2}}-i r z \ln \frac{i+z+\sqrt{r^{2}+(i+z)^{2}}}{z+\sqrt{r^{2}+z^{2}}}$ 
$n=3$ :

$$
\begin{aligned}
& I_{3}^{*}=\left(\frac{2 r^{2}}{3}-\frac{11 z^{2}}{6}\right) \sqrt{r^{2}+z^{2}}-\left(\frac{1}{3}+\frac{2 r^{2}}{3}-\frac{11 z^{2}}{6}+\frac{5 i z}{6}\right) \sqrt{r^{2}+(i+z)^{2}}+\left(\frac{3 r^{2} z}{2}-z^{3}\right) \ln \frac{i+z+\sqrt{r^{2}+(i+z)^{2}}}{z+\sqrt{r^{2}+z^{2}}} \\
& K_{3}^{*}=\left(\frac{13 r z}{8}-\frac{z}{4 r}\right) \sqrt{r^{2}+z^{2}}+\left(\frac{i}{4 r}+\frac{3 i r}{8}-\frac{z}{4 r}-\frac{13 r z}{8}-\frac{i z^{2}}{4 r}+\frac{z^{3}}{4 r}\right) \sqrt{r^{2}+(i+z)^{2}} \\
& -\left(\frac{3 r^{3}}{8}-\frac{3 r z^{2}}{2}\right) \ln \frac{i+z+\sqrt{r^{2}+(i+z)^{2}}}{z+\sqrt{r^{2}+z^{2}}}
\end{aligned}
$$

$n=4:$

$$
\begin{aligned}
& I_{4}^{*}=\left(\frac{55 i r^{2} z}{24}+\frac{25 i z^{2}}{12}\right) \sqrt{r^{2}+z^{2}}-\left(\frac{1}{4}+\frac{3 r^{2}}{8}+\frac{7 i z}{12 r}+\frac{55 i r^{2}}{24}-\frac{13 z^{2}}{12}-\frac{25 i z^{3}}{12}\right) \sqrt{r^{2}+(i+z)^{2}} \\
& -\left(\frac{3 i r^{4}}{8}-3 i r^{2} z^{2}+i z^{4}\right) \ln \frac{i+z+\sqrt{r^{2}+(i+z)^{2}}}{z+\sqrt{r^{2}+z^{2}}}
\end{aligned}
$$$$
\mathrm{K}_{4}^{*}=\left(-\frac{8 \mathrm{ir}^{3}}{15}+\frac{83 \mathrm{ir} \mathrm{z}}{30}-\frac{\mathrm{iz}}{5 \mathrm{r}}\right) \sqrt{\mathrm{r}^{2}+\mathrm{z}^{2}}
$$$$
+\left(\frac{i}{5 r}+\frac{4 i r}{15}+\frac{8 i r^{3}}{15}-\frac{z}{5 r}-\frac{29 r z}{30}-\frac{i z^{2}}{5 r}-\frac{83 i r z^{2}}{30}+\frac{z^{3}}{5 r}+\frac{i z^{4}}{5 r}\right) \sqrt{r^{2}+(i+z)^{2}}
$$$$
+\left(-\frac{3 i r^{3} z}{2}+2 i r z^{3}\right) \ln \frac{i+z+\sqrt{r^{2}+(i+z)^{2}}}{z+\sqrt{r^{2}+z^{2}}}
$$

$\mathrm{n}=5$ :

$$
\begin{aligned}
& I_{5}^{*}=\left(\frac{8 r^{4}}{15}-\frac{607 r^{2} z^{2}}{120}+\frac{137 z^{4}}{60}\right) \sqrt{r^{2}+z^{2}}-\left(\frac{1}{5}+\frac{4 r^{2}}{15}+\frac{8 r}{15}-\frac{47 z^{2}}{60}+\frac{137 z^{4}}{60}-\frac{607 r^{2} z^{2}}{120}+\frac{9 i z}{20}+\frac{161 i r^{2} z}{120}\right. \\
& \left.-\frac{77 i z^{3}}{60}\right) \sqrt{r^{2}+(i+z)^{2}}+\left(\frac{15 r^{4} z}{8}-5 r^{2} z^{3}+z^{5}\right) \ln \frac{i+z+\sqrt{r^{2}+(i+z)^{2}}}{z+\sqrt{r^{2}+z^{2}}}
\end{aligned}
$$




$$
\begin{aligned}
& \mathrm{K}_{5}^{*}=\left(\frac{113 \mathrm{r}^{3} \mathrm{z}}{48}-\frac{97 \mathrm{rz}^{3}}{24}+\frac{\mathrm{z}^{5}}{6 \mathrm{r}}\right) \sqrt{\mathrm{r}^{2}+\mathrm{z}^{2}} \\
& +\left(\frac{1}{6 \mathrm{r}}+\frac{5 \mathrm{ir}}{24}+\frac{5 \mathrm{ir} \mathrm{r}^{3}}{16}-\frac{\mathrm{z}}{6 \mathrm{r}}-\frac{17 \mathrm{rz}}{24}-\frac{113 \mathrm{r}^{3} \mathrm{z}}{48}-\frac{\mathrm{i} \mathrm{z}^{2}}{6 \mathrm{r}}-\frac{41 \mathrm{ir} \mathrm{z}^{2}}{24}+\frac{\mathrm{z}^{3}}{6 \mathrm{r}}+\frac{97 \mathrm{rz}^{3}}{24}+\frac{i \mathrm{z}^{4}}{6 \mathrm{r}}-\frac{\mathrm{z}^{5}}{6 \mathrm{r}}\right) \sqrt{\mathrm{r}^{2}+(\mathrm{i}+\mathrm{z})^{2}} \\
& -\left(\frac{5 \mathrm{r}^{5}}{16}-\frac{15 \mathrm{r}^{3} \mathrm{z}^{2}}{4}+\frac{5 \mathrm{rz} \mathrm{z}^{4}}{2}\right) \ln \frac{\mathrm{i}+\mathrm{z}+\sqrt{\mathrm{r}^{2}+(\mathrm{i}+\mathrm{z})^{2}}}{\mathrm{z}+\sqrt{\mathrm{r}^{2}+\mathrm{z}^{2}}}
\end{aligned}
$$




\section{Figures captions}

Figure1:

Normal stress on the surface, $z=0$, for indenters described by power laws with exponents $\mathrm{n}: 1.5,2.5$ and 3.5

Figure2:

Normal stress in volume, $z=a / 2$, for $n: 1.5,2.5$, and 3.5 . 
Pagidostoph22al Magazine \& Philosophical Magazine Letters $\sigma_{z} / k$

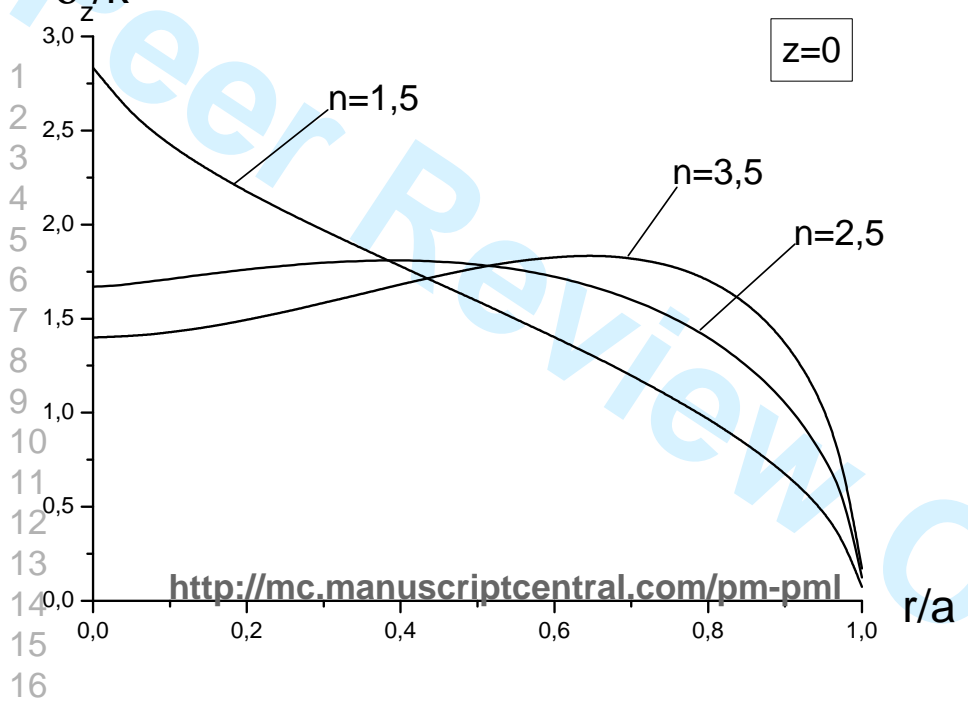


Philosophical Magazine \& Philosophical MagRaige22 dfe2? $\sigma_{z} / k$
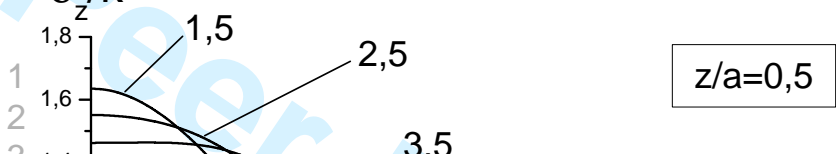

$3,4,5$

$5^{1,2-1}$

$61,0-$

7

80,8

$90,6-$

10

$110,4-$

120,2

140,0

$15^{0,0}$

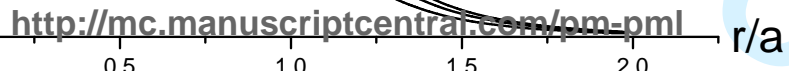

